\title{
Effect of Soil Moisture Content on the Survival of Ganoderma Species and Other Wood-Inhabiting Fungi
}

\author{
TunTschu Chang, Division of Forest Protection, Taiwan Forestry Research Institute, 53 Nanhai Rd., Taipei 100, \\ Taiwan
}

\begin{abstract}
Chang, T. T. 2003. Effect of soil moisture content on the survival of Ganoderma species and other wood-inhabiting fungi. Plant Dis. 87:1201-1204.

The survival of mycelia of Ganoderma australe, G. boninense, G. lucidum, and G. weberianum in colonized wood was measured in soils with different soil matrix potentials. Survival of mycelia of G. australe and G. boninense, which do not produce chlamydospores, buried in plots subjected to different soil moisture treatments, declined rapidly, and the fungi could not be recovered after 9 to 12 weeks. Survival of mycelia of G. lucidum and G. weberianum, which produce chlamydospores, rapidly declined from 0 to 15 weeks of incubation but consistently ranged from 35 to $50 \%$ after 15 weeks of incubation. In regression analyses for each of the four Ganoderma species, there was no difference in the rate of change of mycelial survival over time among different soil moisture treatments. However, when data from only the $-0.20 \mathrm{MPa}$ treatment were used, the rates of change of mycelia survival over time of $G$. australe and G. boninense significantly differed from those of $G$. lucidum and $G$. weberianum. G. australe and $G$. boninense were not recovered from pieces of infested wood subjected to 3 and 1 months of flooding, respectively. In treatments with lower soil moisture, the survival of these two fungi ranged from 80 to $90 \%$ over 2 years. In all soil moisture treatments, survival of G. lucidum and G. weberianum ranged from $80 \%$ to more than $90 \%$ over 2 years. Similarly, seven species of other wood-inhabiting fungi that do not produce chlamydospores were not recovered from pieces of infested wood subjected to 1 or 5 months of flooding, but chlamydospore-producing species were recovered. These results indicate that, regardless of chlamydospore formation, woody debris in soils harboring wood-decay fungi may be important for long-term survival, and chlamydospores of Ganoderma in woody debris enhance the resistance of the fungi to environmental stresses such as flooding. Flooding infested fields may help control those woodinhabiting fungi such as $G$. australe and $G$. boninense that do not produce chlamydospores.
\end{abstract}

Additional keywords: disease management

Ganoderma (Basidiomycota: Ganodermatales) is a genus of wood-inhabiting fungi on monocots, dicots, and gymnosperms. Members of the genus are found around the world from tropical to temperate habitats (12). Some species are saprophytic, but several are pathogens that cause decay in roots, butts, and trunks of living trees. G. australe (Fr.:Fr.) Pat., G. boninense Pat., G. lucidum (W. Curtis:Fr.) P. Karst., and G. weberianum (Bres. \& Henn.) Steyaert are common root pathogens in Taiwan that cause decay and slow decline of numerous orchard and forest tree species (8). Slowly expanding, circular disease patches extending from infection centers can be observed in the field, which indicate that the disease caused by Ganoderma species is spread from diseased to healthy trees by root contact $(1,2)$. Infested

Corresponding author: TunTschu Chang

E-mail: ttchang@serv.tfri.gov.tw

Accepted for publication 12 May 2003.

Publication no. D-2003-0718-01R

(C) 2003 The American Phytopathological Society root debris may be important as inoculum and for long-term survival. Airborne basidiospores can also initiate new infections on freshly cut stumps or logging debris, with subsequent spread to live trees by root contact $(9,11,14)$.

Abundant chlamydospores are produced in pure culture and in woody debris by some species of Ganoderma, such as $G$. lucidum and $G$. weberianum, while others such as $G$. australe and $G$. boninense produce no chlamydospores (6). The role of chlamydospores in the epidemiology of Ganoderma species is unknown, and the long-term survival of chlamydospores and mycelia in soil has not been previously documented. In this study, the survival of chlamydospores and mycelia of Ganoderma species in artificially infested woody debris was assessed in soils with varying moisture levels. In addition, the survival of some other wood-inhabiting fungi in artificially infested woody debris was studied.

\section{MATERIALS AND METHODS}

Fungal isolates, soils, and selective media. All isolates were from fruiting bodies and were identified by the author
(7). For observation of chlamydospores and arthroconidia in culture, the fungi were grown on malt-extract agar (MEA: 2\% malt extract, $2 \%$ agar) at $25^{\circ} \mathrm{C}$ for 4 weeks before microscopic examination.

The silty-loam soil used for this study was collected from below the organic horizon of natural forest soil near Taipei, Taiwan. The unsterilized soil was sifted with a mesh (no. 50) and stored at room temperature before use. Initially, it consisted of $36.7 \%$ sand, $52.6 \%$ silt, and $10.7 \%$ clay, with a moisture content of $10 \%(-0.42$ $\mathrm{MPa})$. The concentration of organic matter was not determined. For treatments requiring less than $10 \%$ soil moisture, the soil was dried at $40^{\circ} \mathrm{C}$ until the desired moisture content was reached. For treatments requiring more than $10 \%$ soil moisture, distilled water was added to the soil until the desired moisture content was reached. The soil matrix potential was adjusted gravimetrically by comparison with a soil moisture retention curve (5). During the experimental period, the temperature in the greenhouse ranged between 15 and $33^{\circ} \mathrm{C}$.

In a preliminary test, a selective medium (4) developed for Phellinus noxius (Corner) G.H. Cunningham was determined to be suitable for isolation of the fungi used in this study. The selective medium consisted of $20 \mathrm{~g}$ of malt extract, $20 \mathrm{~g}$ of agar, $10 \mathrm{mg}$ of benomyl, $10 \mathrm{mg}$ of dicloran, 100 $\mathrm{mg}$ of ampicillin, and $500 \mathrm{mg}$ of gallic acid per liter. The antibiotics and fungicides were added after autoclaving.

Survival of Ganoderma mycelia in soil. Soil matrix potentials were adjusted to $-0.50,-0.20$, and $-0.025 \mathrm{MPa}$, and soils were placed in separate plastic containers (15 cm high $\times 15 \mathrm{~cm}$ diameter). Wetted and autoclaved pieces of cellophane $(2 \times 2$ $\mathrm{cm})$ were placed on MEA plates and inoculated with $G$. lucidum, $G$. boninense, $G$. weberianum, or $G$. australe cultures for 3 weeks at $25^{\circ} \mathrm{C}$. In addition to mycelia, chlamydospores were present on cellophane colonized by $G$. weberianum or $G$. lucidum. Well-colonized cellophane was buried $5 \mathrm{~cm}$ below the soil surface of each plastic container, which was then covered with aluminum foil and sealed with tape to maintain constant soil moisture. The colonized pieces of cellophane were carefully removed from the soil after selected incubation periods $(3,6,9,12,15,18,26$, or 52 weeks), placed on the selective medium, and incubated at $25^{\circ} \mathrm{C}$. Three replicate containers were used for each soil moisture 
level. Thirty pieces of cellophane were used for each replicate. Survival of mycelia was calculated as the percentage of colonized pieces of cellophane from which the tested fungi emerged after 2 weeks of incubation. This experiment was performed twice.

Survival in infested wood buried in soil. Wood sections (about 3 to $5 \mathrm{~cm}$ in diameter and $10 \mathrm{~cm}$ in length) of Cinnamomum camphora (L.) Nees et Eberm. were inoculated with $G$. lucidum, $G$. boninense, G. weberianum, and G. australe. The wood sections were completely colonized after 2 months at $25^{\circ} \mathrm{C}$, when the experiment began. The soil matrix potential was adjusted to $-0.50,-0.30$, or -0.10 $\mathrm{MPa}$, or the soil was flooded with water. Soil of each treatment was placed into a separate plastic container $(100 \mathrm{~cm}$ high $\times$ $40 \mathrm{~cm}$ diameter) to a height of $80 \mathrm{~cm}$, and wood sections were buried $15 \mathrm{~cm}$ below the soil surface. The caps of the containers were sealed with tape to maintain constant soil moisture. Three replicate containers for each soil moisture treatment were used. Three wood sections were used for isolation of each replicate. When the wood sections were used to test for fungal survival, they were washed with tap water and blotted dry, and 50 wood fragments (about $3 \times 6 \mathrm{~mm}$ ) were cut from each wood section and placed on selective medium at $25^{\circ} \mathrm{C}$. Survival in infested wood was calculated as the percentage of wood fragments from which the tested fungi emerged after 2 weeks of incubation. This experiment was conducted twice.

The methods used for testing the survival of the other 16 wood-inhabiting polypore fungi (Table 1) were the same as those for Ganoderma species, except that the soil matrix potential was adjusted to $-0.50 \mathrm{MPa}$ or the soil was flooded with water.

Statistical analyses. Survival (\%) of mycelia and infested wood was arcsine transformed (survival/100) ${ }^{1 / 2}$. The transformed data were analyzed by regression analysis with the PROC GLM procedure of PC-SAS (SAS Institute, Cary, NC) to compare the slope from the empirical regression of fungal survival against time (3). Data were combined from two experimental trials with three replications.

\section{RESULTS}

Survival of Ganoderma mycelia in soil. The survival of mycelia buried in soil at $-0.025 \mathrm{MPa}$ declined most rapidly for $G$. australe and $G$. boninense, and these fungi could not be recovered at 9 or 12 weeks, respectively (Fig. 1A and B). Their mycelia buried in soil at $-0.50 \mathrm{MPa}$ had higher recovery rates than those in the -0.20 and $-0.025 \mathrm{MPa}$ soil moisture treatments. Regardless of soil moisture levels, G. australe and $G$. boninense were not recovered after 15 weeks. No difference in the rate of change of mycelial survival over time ( $P=$ 0.25 for $G$. australe and $P=0.31$ for $G$. boninense) was observed among the different soil matrix potential treatments.

For G. lucidum and G. weberianum, survival of mycelia in all soil moisture treatments declined from 0 to 15 weeks of incubation (Fig. 1C and D). However, survival of mycelia ranged from 35 to $50 \%$ after 18 weeks of incubation. No difference in the rate of change of mycelial survival over time was seen for G. lucidum or $G$. weberianum $(P=0.64$ for $G$. lucidum and $P=0.58$ for $G$. weberianum) among the different soil matrix potential treatments.

Since there was no difference in the rate of change of mycelial survival over time for each of the four Ganoderma species among the different soil matrix potentials, survival of the four Ganoderma species was compared only at the $-0.20 \mathrm{MPa}$ soil matrix potential. The rates of change of mycelial survival over time of $G$. australe and $G$. boninense, which produced no chlamydospores, significantly differed $(P<$ $0.05)$ from those of $G$. lucidum and $G$. weberianum, which produced chlamydospores.
Survival of Ganoderma in infested wood. $G$. australe and $G$. boninense were not recovered from pieces of infested wood subjected to 3 and 1 months of flooding, respectively. However, in treatments with lower soil moistures, $G$. australe and $G$. boninense survival ranged from $80 \%$ to more than $90 \%$ over 2 years of study (Fig. $2 \mathrm{~A}$ and $\mathrm{B})$. Slopes for these survival rates did not significantly differ $(P>0.05)$ among treatments when the flooding treatment was excluded.

For G. lucidum or $G$. weberianum, slopes for survival in infested wood with time did not significantly differ among treatments including flooding. In all soil moisture treatments, $G$. lucidum and $G$. weberianum survival ranged from $80 \%$ to more than $90 \%$ over the 2 years of study (Fig. 2C and D).

Survival of other fungi in infested wood in soil. Survival of 16 woodinhabiting fungi in soils with a $-0.50 \mathrm{MPa}$ soil matrix potential ranged from $70 \%$ to $100 \%$ over the 2 years (Table 1). For each species, slopes for survival of these fungi with time did not differ significantly $(P<$ 0.05 ) from a slope of zero. However, when these fungi in infested wood were placed in flooded soils, four of them (Bjerkandera adusta (Willd. ex Fr.) P. Karst., Polyporus grammocephalus Berk., Phellinus longisetulosus Bond. et Herr., and Trametes versicolor (L.:Fr.) Pilat) were not recovered after 1 month of treatment, while three of them (Abortiporus biennis (Bull. ex Fr.) Sing., Schizopora flavipora (Cke.) Ryvarden, and Trametes hirsuta (L.:Fr.) Pilat) were not recovered after 5 months (Table 1). These seven species did not produce chlamydospores in culture. Regardless of soil moisture levels, the survival of the nine species that produced chlamydospores ranged from 70 to $100 \%$ after 2 years (Table 1). For each of these nine species, slopes for survival with time were not significantly different from a slope of zero $(P>0.05)$.

Table 1. Survival $(\%)$ of 16 wood-inhabiting fungi in artificially infested wood sections buried in soils with flooding or a $-0.50 \mathrm{MPa}$ soil matrix potential after four incubation periods (months)

\begin{tabular}{|c|c|c|c|c|c|c|c|c|c|c|}
\hline \multirow[b]{2}{*}{ Fungus and culture no. } & \multirow[b]{2}{*}{ Chlamydospores } & \multirow[b]{2}{*}{ Arthroconidia } & \multicolumn{4}{|c|}{ Flooding } & \multicolumn{4}{|c|}{$-0.50 \mathrm{MPa}$} \\
\hline & & & 1 & 5 & 12 & 24 & 1 & 5 & 12 & 24 \\
\hline Abortiporus biennis TFRI 274 & $-^{\mathrm{a}}$ & + & 20 & 0 & 0 & 0 & 90 & 85 & 80 & 85 \\
\hline Bjerkandera adusta TFRI 180 & - & + & 0 & 0 & 0 & 0 & 80 & 85 & 85 & 75 \\
\hline Coriolus brevis TFRI 552 & + & - & 90 & 85 & 80 & 85 & 95 & 85 & 90 & 80 \\
\hline Daedalea dickinsii TFRI 305 & + & - & 85 & 90 & 85 & 90 & 85 & 85 & 90 & 75 \\
\hline Fomitopsis cajanderi TFRI 102 & + & - & 100 & 85 & 75 & 80 & 100 & 90 & 90 & 85 \\
\hline Inonotus rickii TFRI 712 & + & - & 85 & 90 & 70 & 85 & 90 & 80 & 85 & 75 \\
\hline Perenniporia formosana TFRI 375 & + & - & 100 & 100 & 85 & 90 & 85 & 90 & 80 & 80 \\
\hline Perenniporia latissima TFRI 281 & + & - & 100 & 95 & 100 & 85 & 100 & 85 & 80 & 80 \\
\hline Phaeolus schweinitzii TFRI 434 & + & - & 100 & 85 & 95 & 90 & 95 & 100 & 80 & 75 \\
\hline Polyporus arcularius TFRI 597 & + & - & 95 & 85 & 85 & 80 & 95 & 85 & 70 & 85 \\
\hline Polyporus grammocephalus TFRI 326 & - & + & 0 & 0 & 0 & 0 & 85 & 100 & 80 & 80 \\
\hline Rigidoporus ulmarius TFRI 763 & + & - & 80 & 80 & 75 & 70 & 80 & 75 & 70 & 70 \\
\hline Phellinus longisetulosus TFRI 201 & - & + & 0 & 0 & 0 & 0 & 90 & 95 & 80 & 70 \\
\hline Schizopora flavipora TFRI 401 & - & - & 25 & 0 & 0 & 0 & 85 & 80 & 75 & 90 \\
\hline Trametes hirsuta TFRI 211 & - & - & 20 & 0 & 0 & 0 & 95 & 85 & 90 & 70 \\
\hline Trametes versicolor TFRI 31 & - & - & 0 & 0 & 0 & 0 & 95 & 90 & 70 & 80 \\
\hline
\end{tabular}

${ }^{a}$ Presence (+) or absence (-) in culture. 


\section{DISCUSSION}

Woody debris infested with G. australe, G. boninense, G. lucidum, and G. weberianum survived significantly longer than mycelium when buried in soil. Mycelia of $G$. lucidum and $G$. weberianum, which produced chlamydospores, survived over 52 weeks of incubation in soil, but mycelia of $G$. australe and $G$. boninense, which do not produce chlamydospores, survived only up to 12 weeks of incubation. In addition, $G$. lucidum and $G$. weberianum in woody material survived in flooded soil, but $G$. australe and $G$. boninense did not. Chlamydospores appear to be important to survival, and woody material infested with Ganoderma species, regardless of chlamydospore production, appears to be more important than mycelia per se for longterm survival of these fungi in soil.

Survival of 16 other wood-inhabiting fungi in soil was similar to that of the four Ganoderma species. Chlamydospores of these wood-inhabiting fungi may be important for long-term survival, and these structures may provide resistance to severe environmental stresses such as soil flooding. These results are consistent with those reported for woody debris infested with Phellinus noxius (5). Arthroconidia are produced by some basidiomycetous woodinhabiting fungi (13), but arthroconidia of $P$. noxius do not appear to be important survival structures (5). In our study, the four species of wood-inhabiting fungi that produced arthroconidia but not chlamydospores did not survive in flooded soil.

Submersion of wood in water has been used to prevent postharvest colonization by wood-decay fungi (10). The benefit might be due to the activities of anaerobic microorganisms. In this study, when wood sections colonized by test fungi that produced chlamydospores were submerged in water, the fungi survived for over 2 years. However, when wood sections colonized by test fungi that did not produce chlamydospores were submerged in water, the fungi died within 3 months. When wood sections colonized by $P$. noxius, which does not contain chlamydospores, were submerged in water, the fungus died within 1 month
(5). Thus, for disease management of root and butt rot caused by wood-inhabiting fungi that do not produce chlamydospores, flooding infested fields might eliminate the inoculum source in infested wood. However, the pieces of infested wood that were tested in this study were relatively small, and field studies are required to test this hypothesis.

\section{ACKNOWLEDGMENTS}

I thank H. D. Hu of National Taiwan University and C. C. Liao of the Taiwan Agricultural Research Institute for their critical review of this manuscript, and H. R Yen and W. R. Wang for technical assistance. This paper is contribution no. 215 of the Taiwan Forestry Research Institute.

\section{LITERATURE CITED}

1. Adaskaveg, J. E., and Gilbertson, R. L. 1987. Infection and colonization of grapevines by Ganoderma lucidum. Plant Dis. 71:251-253.

2. Bakshi, B. K., Reddy, M. A. R., and Singh, S 1976. Ganoderma root rot mortality in khair (Acacia catechu Willd.) in reforested stands. Eur. J. For. Pathol. 6:30-38.

3. Benson, D. M., and Baker, R. 1974. Epidemiology of Rhizoctonia solani pre-emergence damping-off of radish: Survival. Phy-
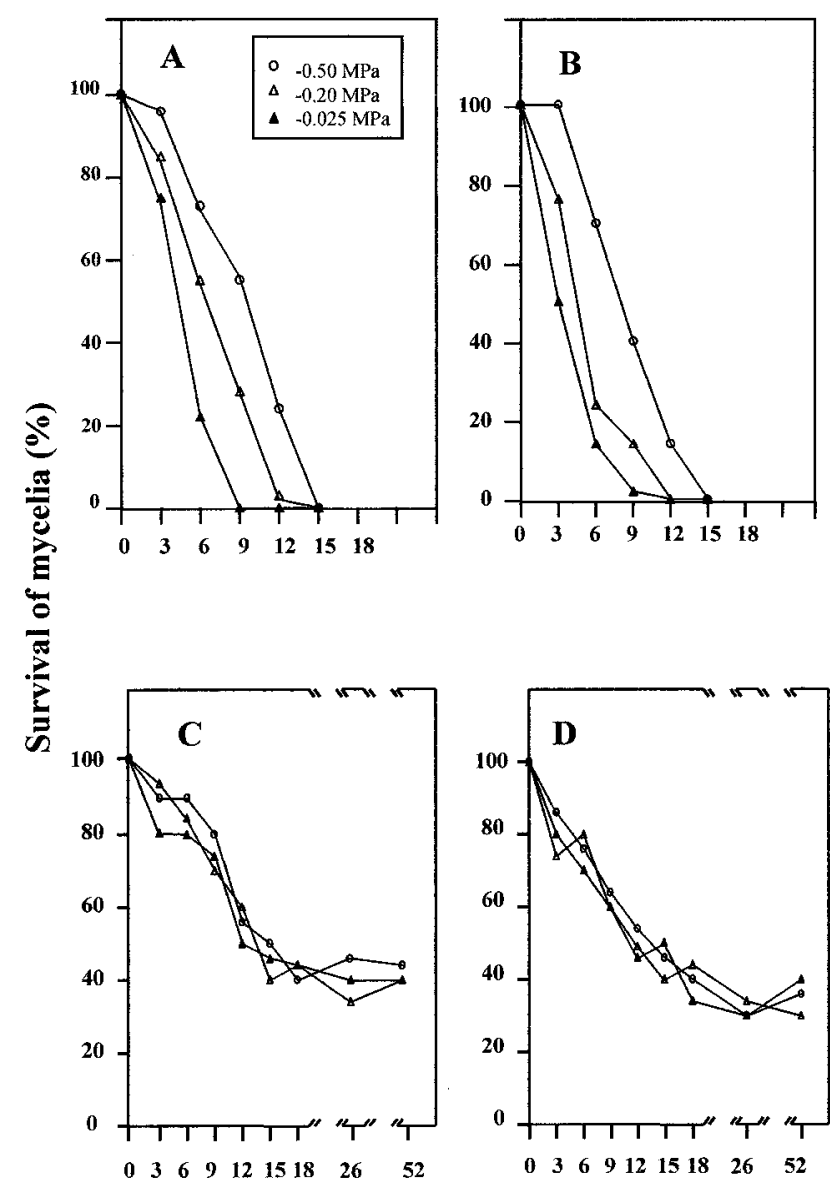

Weeks after incubation

Fig. 1. Survival of mycelia of four Ganoderma species buried in soil with various soil moisture treatments for different incubation times. Each value is the mean of three replicates averaged over two experimental trials. Survival of mycelia was calculated as the percentage of colonized cellophane pieces from which the fungi grew after 2 weeks of incubation. A, G. australe, B, G. boninense, $\mathbf{C}$, G. lucidum, D, G. weberianum.

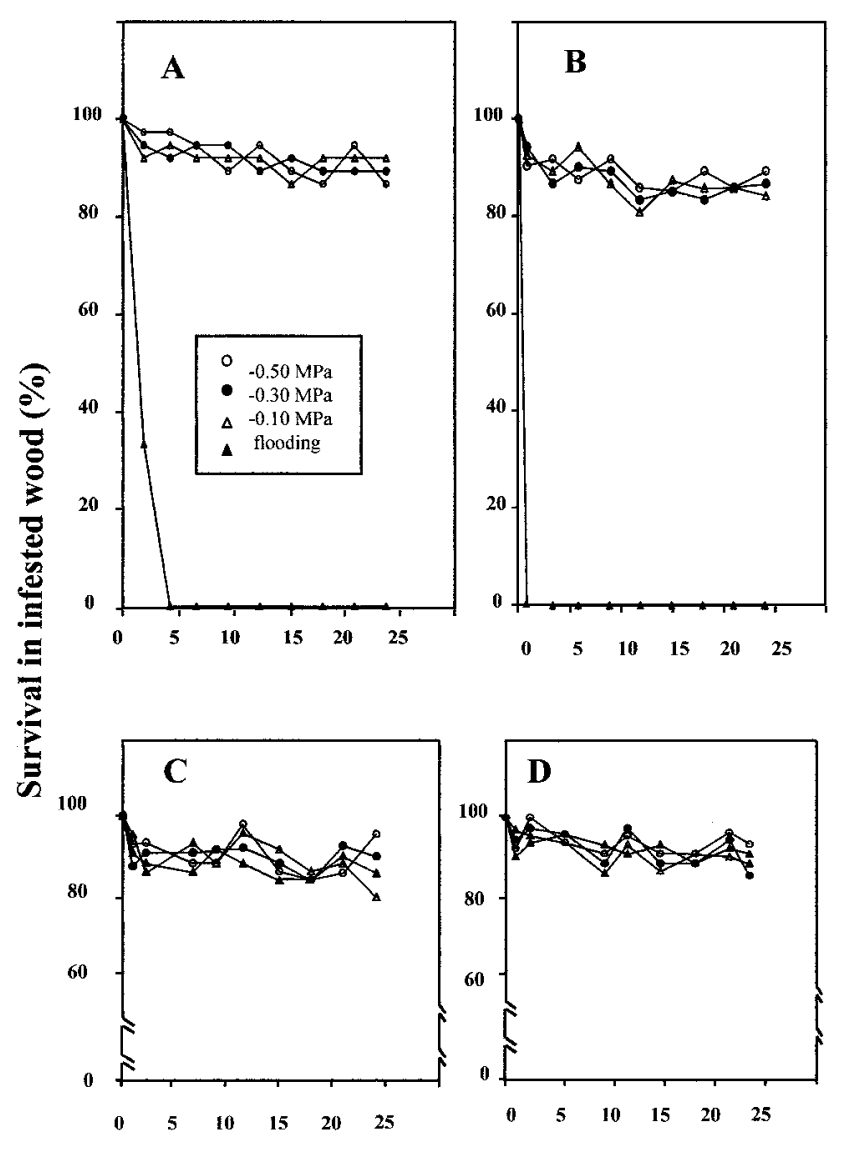

Months after incubation

Fig. 2. Survival of four Ganoderma species in artificially infested wood sections buried in soils with various soil moisture treatments for different incubation times. Each value is the mean of three replicates averaged over two experimental trials. Survival in infested wood was calculated as the percentage of wood fragments from which the fungi grew after 2 weeks of incubation. A, G. australe, B, G. boninense, C, G. lucidum, D, G. weberianum. 
topathology 64:1163-1168.

4. Chang, T. T. 1995. A selective medium for Phellinus noxius. Eur. J. For. Pathol. 25:185190.

5. Chang, T. T. 1996. Survival of Phellinus noxius in soil and in the roots of dead host plants. Phytopathology 86:272-276.

6. Chang, T. T., Chiu, W. H., and Hua, J. 1996. The cultural atlas of wood-inhabiting Aphyllophorales in Taiwan, vol. 1. Food Industry Research and Development Institute, Taipei, Taiwan. Mycol. Monogr. 10.

7. Chang, T. T., Chou, W. N., Wang, Y. Z., and Ju, Y. M. 2001. Macrofungi of Taiwan. Council of
Agriculture, Taipei, Taiwan. (In Chinese.)

8. Chang, T. T., Hsieh, H. J., Chang, R. J., and Fu, C. S. 1999. Common tree diseases in Taiwan. Taiwan Forestry Research Institute, Taipei, Taiwan. Tech. Rep. 98. (In Chinese.)

9. Darus, A., Seman, I. A., and Azahari, M. 1996. Spread of Ganoderma boninense and vegetative compatibility studies of a single palm field isolates. Pages 317-329 in: Proc. PORIM Int. Palm Oil Congress, Selangor, Malaysia. Palm Oil Research Institute of Malaysia, Kuala Lumpur.

10. Rayner, A. D. M., and Boddy, L. 1988. Fungal Decomposition of Wood: Its Biology and
Ecology. John Wiley \& Sons, New York.

11. Sanderson, F. R., and Pilotti, C. A. 1997 Ganoderma basal stem rot: An enigma, or just time to rethink an old problem? Planter (Kuala Lumpur) 73:489-493.

12. Sinclair, W. A., Lyon, H. H., and Johnson, W T. 1987. Diseases of trees and shrubs. Cornell University Press, Ithaca, NY.

13. Stalpers, J. A. 1978. Identification of woodinhabiting Aphyllophorales in pure culture. Studies in Mycology 16. Centraalbureau voor Schimmelcultures, Baarn, Netherlands.

14. Turner, P. D. 1965 . Infection of oil palms by Ganoderma. Phytopathology 55:937. 